\title{
A Study of Serum Zinc level in Patients with Acute Myocardial Infarction
}

\author{
MR Quader ${ }^{1}$, S Rahman ${ }^{2}$, SK Saha ${ }^{3}$
}

\begin{abstract}
:
Acute myocardial infarction is one of the most important reason of death in the world. There are some established risk factors of acute myocardial infarction (AMI), but measurement of trace element like zinc can be helpful in the prevention and better management of AMI. The aim of this study was to estimate serum zinc in AMI patients. This is a case control type of study carried out in the Department of Biochemistry, Dhaka Medical College, Dhaka during the period of January 2015 to December 2015 with a total number of 100 study subjects. Acute myocardial infarction patients were selected as case (50) from coronary care unit (CCU), Department of Cardiology, Dhaka Medical College Hospital. Normal healthy individuals were selected as control (50) from the attendants of patients, relatives and doctors. Serum level of zinc was assessed for both case and control groups. The mean values of the variable were compared between them by statistical analysis using SPSS version 16. For all the statistical analysis $\mathrm{p}<0.05$ was considered as significant. The mean values of serum zinc were $73.18 \pm 21.14 \mu \mathrm{g} / \mathrm{dl}$ in cases. The mean values of serum zinc were $11.04 \pm 23.06 \mu \mathrm{g} / \mathrm{dl}$ in control group. Significant differences were found in mean values between case and control groups and differences were very highly significant ( $p$-value $<0.001$ ). In AMI serum zinc levels were found to decrease in this study. Serum zinc is an important trace element act as cofactor in many biochemical reactions. Decrease level of this important trace element may contribute to pathogenesis of AMI. So with other biochemical risks parameters, routine assessment of serum zinc level is advocated, which might be helpful for prevention and better management of AMI.
\end{abstract}

Key words: Myocardial infarction, serum Zinc level.

\section{Introduction:}

Myocardial infarction is one of the dangerous manifestations of coronary artery disease $\&$ is one of the commonest cause of mortality. It has now become an important health problem despite advancement in diagnosis. Bangladesh has been experiencing epidemiological transition from communicable disease to non-communicable disease (NCD). The overall mortality rate has decreased significantly over the last couple of decades. But deaths due to chronic diseases, specially the 'fatal four' i.e. cardiovascular disease (CVD), cancer, chronic respiratory disease and diabetes, are increasing in an alarming rate ${ }^{1}$. People of South Asia have a 1.5 -fold greater susceptibility to AMI than the general population ${ }^{2}$. The exact prevalence of AMI in Bangladesh is not known. Recent data

1. Dr. Mohammad Rezaul Quader, MBBS, M Phil (Biochemistry), Assistant Professor, Dept. of Biochemistry, Faridpur Medical College, Faridpur.

2. Dr. Sharmin Rahman, MBBS, M Phil (Pharmacology), Associate Professor, Ibrahim Medical College, Dhaka.

3. Dr. Suranjit Kumar Saha, MBBS, FCPS (Medicine), Junior Consultant, Medicine, Pirojpur Sadar Hospital, Pirojpur.

Address of correspondence :

Dr. Mohammad Rezaul Quader, MBBS, M Phil (Biochemistry)

Assistant Professor, Dept. of Biochemistry, Faridpur Medica

College, Faridpur. Mobile: +88-01711931077,

E-mail: drrezaul.quader@gmail.com indicates the prevalence between $1.85 \%$ and $3.4 \%$ in rural and $19.6 \%$ in an urban sample of working professionals ${ }^{1}$.

AMI is defined as a part of acute coronary syndrome characterized by a typical clinical syndrome consisting of chest pain, dyspnea with rise \& fall in troponin or CK-MB to values greater than $99 \%$ of a normal reference population ${ }^{3}$. Many prospective studies have implicated metal ions \& lipids in the genesis of Myocardial infarction. Therefore, attention is being focused on metals as decrease level act as risk factors for AMI.

Zinc is one of the essential trace elements involved in nearly all aspects of cellular metabolism \& is essential for cell division \& DNA synthesis. Availability of zinc regulates the rate of synthesis of nucleic acids \& proteins suggesting that its availability may critically influence tissue reparative processes ${ }^{4}$.

Zinc is mainly an intracellular element. About $60 \%$ of zinc is present in muscle \& $30 \%$ in bone. It is also present in liver, brain \& skin. RDA of zinc is about 10$15 \mathrm{mg} /$ day for adult \& $15-20 \mathrm{mg} /$ day for pregnant women ${ }^{5}$. 
Zinc deficiency is usually due to insufficient dietary intake but can be associated with malabsorption, acrodermatitis enteropathica, chronic liver disease, chronic renal disease, sickle cell disease, diabetes, malignancy and other chronic illnesses. Because of the widespread prevalence of zinc deficiency \& the multitude of its essential biological function, nutritional correction of zinc deficiency may have major impact on different disease states ${ }^{6}$.

Serum zinc levels were found low concentration in blood after acute tissue injury irrespective of its origin, including myocardial infarction, which produces some of the most striking falls. Levels of zinc fall by $30 \%$ within one or two days following AMI. At the same time the extent of fall also correlated with the complications of AMI. Therefore it may serve as an indicator in assessing the prognosis following $\mathrm{AMI}^{4}$.

This study was designed to investigate the change in serum levels of zinc in AMI patients.

\section{Materials and Methods:}

This case control study was conducted in the Department of Biochemistry, Dhaka Medical College, Dhaka, Bangladesh. The duration of the study was from January 2015 to December 2015.

The study comprises of fifty cases of AMI admitted in $\mathrm{CCU}$ and fifty normal healthy individuals (Attendants of patients, relatives \& doctors) as control using purposive sampling technique. Diagnosed case of AMI of both sexes Admitted within 72 hours of symptoms and age 40-65 years where included as cases whereas healthy adult of both sexes with age range 40-65 years were included as controls Patient with history of IHD, congenital cyanotic heart disease, CKD, DM, COPD and Malignancy, patient with history of medication like lipid lowering drug, magnesium supplement, zinc supplement, antiplatelet drug, any acute inflammatory conditions like RTI, UTI, and patients with pregnancy with and lactation. were excluded both in case and control group.

With all aseptic precaution $8 \mathrm{ml}$ venous blood was drawn from anterior cubital vein in a disposable plastic syringe and immediately transferred to a dry clean test tube which was allowed to clot. Then serum was separated after centrifuging at 3000rmp for 10 minutes and was collected in ependrop tube, labeled appropriately. Serum zinc was estimated by colorimetric method at the Department of Biochemistry, Dhaka Medical College. Normal level of serum Zinc is $80-120 \mu \mathrm{g} / \mathrm{dl}$, the cut of value for the study was $100 \mu \mathrm{g} / \mathrm{dl}$.
A preformed questionnaire sheet was used to record information. Informed written consent was taken from the participants. Initial evaluation of the study population was done by taking history (Demographic, family $\mathrm{H} / \mathrm{O}$ hypertension, diabetes, obesity and relevant drug history). Pulse, blood pressure, height, weight and BMI were measured and laboratory findings of serum zinc were recorded in the preformed data collection sheet. Cardiac marker (Troponin-I) level was collected from patient's record book. Statistical analysis was performed with SPSS, version 16. All data were processed to computed mean and standard deviation. Difference of mean among the case and control groups were compared by unpaired ' $t$ ' test, chi-square test and fisher exact test and determination of correlation between variables were done by Pearson's correlation coefficient test. For all statistical analysis $p<0.05$ was considered as significant.

Table-I: Distribution of patients according to demographic profile

\begin{tabular}{lllll}
\hline Characteristics & \multicolumn{5}{c}{ Case Control Test statistics } & p value \\
\hline Sex & & & & \\
\hline Female & 14 & 16 & $\mathrm{X}^{2}=0.19$ & 0.414 \\
Male & 36 & 34 & $\mathrm{df}=1$ & \\
Total & 50 & 50 & & \\
\hline Age group (years) & & & \\
\hline $40-50$ & 17 & 21 & Mean age $=53.30 \pm 6.44$ year \\
$50-60$ & 26 & 23 & $(40-65)$ & 0.711 \\
$60-70$ & 7 & 6 & $\mathrm{X}^{2}=0.682$ & \\
Total & 50 & 50 & $\mathrm{df}=2$ & \\
\hline
\end{tabular}

*Chi square test was done at the level of $95 \%$ confidence interval.

Table-I shows the sex distribution in case and control group. The sexes are equally distributed between case and control ( $p>0.05)$. It also shows age group for 100 sample size. The minimum age was 40 years and maximum age was 65 years with the mean age $53.30 \pm$ 6.44 years. The age group are equally distributed between case and control $(\mathrm{p}>0.05)$.

Table-II: Level of Serum Zinc between case and Control

\begin{tabular}{cllll}
\hline Parameter & $\begin{array}{l}\text { Case } \\
\text { (mean } \pm S D)\end{array}$ & $\begin{array}{l}\text { Control } \\
\text { (mean } \pm S D)\end{array}$ & t & p-value \\
\hline S.Zinc( $\mu \mathrm{g} / \mathrm{dl})$ & $73.18 \pm 21.14$ & $110.4 \pm 23.06$ & 8.37 & $<0.001$ \\
& $(37.4-137)$ & $(78-172.60)$ & & \\
\hline
\end{tabular}

*Unpaired $t$ test was done with $95 \%$ confidence interval. 
The ranges are shown within parenthesis.

Table-II shows that Mean \pm SD of S.Zinc levels were $73.18 \pm 21.14$ and $110.4 \pm 23.06$ in case and control respectively. The level of S.Zinc is significantly low in case group in comparison with control $(\mathrm{p}<0.001)$.

\section{Serum Zinc $(\mu \mathrm{g} / \mathrm{dL})$}

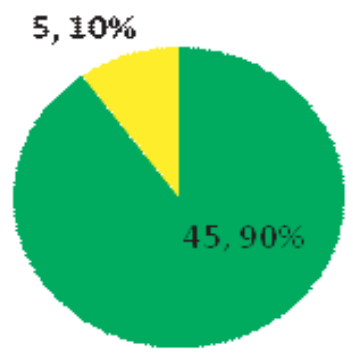

$$
\begin{aligned}
& \text { 5. Zinc }<100 \\
& \text { Ig/dl } \\
& \text { s. Zinc } \times 100 \\
& \text { Hg/dL }
\end{aligned}
$$

\section{Figure-1: Prevalence of Low Serum Zinc in case.}

Fig- 1 shows that among the case 45 persons having

\begin{tabular}{|c|c|c|c|c|c|}
\hline S.Zinc( $\mu \mathrm{g} / \mathrm{dl})$ & $\begin{array}{l}\text { Case } \\
\text { ( MI) }\end{array}$ & $\begin{array}{l}\text { Control } \\
\text { (Normal) }\end{array}$ & Total & $\begin{array}{l}\text { Test } \quad P \\
\text { statistics }\end{array}$ & $\begin{array}{l}\text { P-value } \\
\text { s }\end{array}$ \\
\hline$<100$ & 45 & 22 & 67 & $X^{2}=23.926$ & \\
\hline$>100$ & 5 & 28 & 33 & $d f=1$ & $<0.001$ \\
\hline Total & 50 & 50 & 100 & & \\
\hline
\end{tabular}
Serum Zinc level $<100 \mu \mathrm{g} / \mathrm{dl}(90 \%)$ and 5 persons having Serum Zinc level $>100 \mu \mathrm{g} / \mathrm{dl}(10 \%)$.

\section{Table-III:Association of Serum Zinc with cases.}

*Chi-square test was done to measure the level of significance

Table-III shows decreased serum zinc level has very strong association ( $\mathrm{p}$ value $<0.001$ ) with AMI patient.

\section{Discussion:}

Zinc is a vital element in maintaining the normal structure \& physiology of cells. The fact that it has an important role in states of cardiovascular diseases has been studied \& described by several research groups \& observed to have protective effects in coronary artery disease. Intracellular zinc plays a critical role in the redox signaling pathway,whereby certain triggers such as ischemia \& infarction lead to release of zinc from proteins \& cause myocardial damage. In such states replenishing with zinc has been shown to improve cardiac function \& prevent further damage. Thus the area of zinc homeostasis is emerging in cardiovascular disease research ${ }^{7}$. According to Halsted \& Smith, the value of serum zinc decreased within 24-48 hours \& low values persisted for two weeks ${ }^{8}$.
In the present study the sexes are equally distributed between case and control, there was no significant difference found in gender between case and control group. There was no significant difference found in age of the case and control, age of the respondent were equally distributed. The study report has inverse association between serum zinc levels and acute myocardial infarction. The mean values of serum zinc were $73.18 \pm 21.14 \mu \mathrm{g} / \mathrm{dl}$. In control group the mean values of serum zinc were $110.4 \pm 23.06 \mu \mathrm{g} / \mathrm{dl}$. Thus, significant difference was found in mean values between case and control groups. Some previous studies showed similar significant decrease in serum zinc level of AMI patient when compared with the corresponding control and it was clear that zinc level of the AMI groups were significantly lower than that of control groups ${ }^{9,10}$.

\section{Conclusion:}

In present study it is observed that serum zinc level appears to be low in patients with acute myocardial infarction. The hypozincemia may be involved in the induction \& sustaining of myocardium tissue injury. Serum zinc is an important trace element act as cofactor in many biochemical reactions. Decrease level of this important trace element may contribute to pathogenesis of AMI. So with other biochemical risk parameters, routine assessment of serum zinc level is advocated, which might be helpful for prevention and better management of AMI. Study with large sample will be helpful to evaluate the definite role of serum zinc in acute myocardial infarction.

\section{References :}

1. Islam AM, Majumder A. Coronary artery disease in Bangladesh: A review. Indian heart journal 2013; 65(4):424-35.

2. Barakat K, Wells Z, Ramdhany S, Mills P, Timmis A. Bangladeshi patients present with non-classic features of acute myocardial infarction and are treated less aggressively in east London, UK. Heart. 2003; 89(3):276-9.

3. Alpert JS, Thygesen K, Antman E, Bassand JP et al. Myocardial infarction redefined-a consensus document of Joint European Society of Cardiology/American College of Cardiology Committee for the redefinition of myocardial infarction. J Am Coll Cardilol. 2000; 36:959-69.

4. Shekokar P, Kaundiny S. Effect of acute myocardial infarction on serum zinc level.Indian Journal of Basic \& Applied Medical Research. 2013; 3(1):80-87.

5. Grandham\& Rajeev. Zinc Metabolism, Health \& Medicine. 2014.

6. Deshpande JD, Joshi MM, Giri PA. The trace element of major importance in human nutrition \& health. Int J Med Sci Public Health. 2013; 2:1-6.

7. Little PJ, Bhattacharya R, Moreyra AE, Korichneva IL. Zinc \& cardiovascular disease. Nutrition 2010; 26(11-12):1050-57.

8. Halsted JA, Smith JC, JR. Plasma- zinc in health \& disease. Lancet 1970; i:322-24

9. Dasti MA, Hashmi SFA, Baloch GH, Shas SZA. Acute myocardial infarction serum zinc level in patients. Professional Med J.2013; 20(4):556-61.

10. Nazir S, Ullah E, Hussain S, Bukhari SA Study of Serum zinc levels among patients of coronary artery disease conducted in a Tertiary Care Hospital. Biomedica 29. 2013 